\title{
Desenvolvimento: ambigüidades de um conceito difuso*
}

\section{Development: ambiguities of a diffuse concept}

Dieter Rugard Siedenberg ${ }^{1}$

\begin{abstract}
Resumo
Durante as últimas cinco décadas, o termo "desenvolvimento" ocupou lugar de destaque nas ciências sociais e econômicas, na discussão política, na mídia e nas políticas públicas. Apesar disso, nunca houve unanimidade em torno desse conceito e, principalmente, sobre como o desenvolvimento pode ou deve ser fomentado. Este artigo busca explicitar, através de uma abordagem epistêmico-sistemática, diferentes nuanças, elementos e aspectos relacionados ao conceito de desenvolvimento, tomando como referência as categorias e terminologias que a biologia explicita em relação aos processos de mudança. A observação de distinções, relações e mecanismos que ocorrem na dimensão biótica podem contribuir significativamente na definição e na dinâmica de processos de mudanças sociais e econômicas.
\end{abstract}

Palavras-chave: processos de mudança; desenvolvimento; crescimento; evolução.

\begin{abstract}
During the last five decades the term "development" has occupied a central place in the Social Sciences, in Economical Sciences, in political circles, in the mass communication media as a whole as well as in the establishment of public policies. However, the term is questioned by many people and there are concerns about how it could and should be promoted. This article intends to clarify the different elements and aspects related to the term "development", employing an epistemic/systematic approach. It takes as reference the categories and terminology Biology employs concerning the processes of change. The observation of distinctions, relations and mechanisms that take place in the biotic dimension, may bring a significant contribution to the definition and dynamics of changing of social and economical processes.
\end{abstract}

Key words: processes of change; development; growth; evolution.

\section{Introdução}

Este artigo tem por objetivo resgatar de forma sucinta a trajetória de um conceito-chave em diversas áreas das ciências humanas e sociais, que é o conceito de desenvolvimento.

Há um certo consenso entre os pesquisadores dessas áreas em fixar a década de 1950 como o período onde esse conceito se consolidou, sobretudo nas discussões acadêmicas. Foi a partir dessa década que a aplicação do conceito em estratégias e políticas de desenvolvimento contribuiu, por um lado, para a integração das áreas do conhecimento, ainda que, por outro lado, também seja verdade que a implementação e a avaliação de tais estratégias tenham contribuído para o surgimento de posições ideológicas antagônicas sobre o assunto.

\footnotetext{
Este artigo foi publicado originalmente na revista Desenvolvimento em Questão, n⿳⺈ 3 - jan./jun. 2004, do Programa de Pós-Graduação em Desenvolvimento, Gestão e Cidadania, da Unijui. A versão apresentada nesse paper foi revisada, ligeiramente reestruturada e recebeu alguns enxertos temáticos complementares, efetuados pelo próprio autor.

${ }^{1}$ Doutor em Desenvolvimento Regional-Universitat Tuebingen/Alemanha. Professor do Mestrado em Desenvolvimento da UNIJUI e do Mestrado e do Doutorado em Desenvolvimento Regional da UNISC. Endereço : Rua do Comércio, 3000 - Bairro Universitário - IJUI - RS - Brasil - - 98.700-000. E-mail: dieterrs@unijui.tche.br.
}

Artigo recebido em agosto de 2006e e aceito para publicação em outubro de 2006. 
Mesmo nos projetos recentes de desenvolvimento socioeconômico de países ou regiões fica evidente que a concordância tácita sobre a complexidade de tais processos persiste, assim como também persiste a discordância explícita sobre as formas de implementação e condução das políticas de desenvolvimento. Todavia, o que se observa no contexto dos projetos de desenvolvimento implementados nas últimas décadas, é que a primazia de fatores essencialmente econômicos sobre os demais fatores (sociais e ambientais, por exemplo) vem perdendo fôlego. No mundo acadêmico, a proliferação de estudos que apontam e esmiúçam as mais diferentes nuanças do desenvolvimento, praticamente, inviabilizam uma visão geral do problema, a ponto de Sachs (apud Nuscheler 1995, p.178) referir-se ao conceito da seguinte forma:

Entrementes, desenvolvimento tornou-se uma palavra amorfa, semelhante a uma ameba. O termo não significa nada, porque seus contornos se esvaem... Quem utiliza esse termo não identifica absolutamente nada, mas preserva para si todas as boas intenções deste mundo. Apesar de não ter conteúdo, o termo tem uma função: em nome de um objetivo superior [a utilização do conceito] consagra toda e qualquer proposta ao direito de ser consumada. Desenvolvimento é um termo tão vazio quanto um mero plus.

Assim, não é de admirar que Sérgio Boisier, por exemplo, ao se referir aos processos de desenvolvimento local, pergunte de forma lapidar: "de qué estamos hablando?" (BOISIER 2000). Outros optam por adjetivar o conceito (desenvolvimento sustentável, por exemplo), imaginando estarem definindo o termo com maior precisão através desse recurso. Já Amartya Sen arrisca vincular o conceito ao processo de expansão das diferentes dimensões de liberdade que as pessoas desfrutam (SEN 2000), inovando na tentativa de definir desenvolvimento, ao propor uma configuração substantivo-substantivo (desenvolvimento como liberdade). Porém, o que se observa é que todas essas abordagens e conjunções não são suficientes para auxiliar na explicitação definitiva do conceito. Desenvolvimento continua sendo um conceito ambíguo e difuso, ou seja, um conceito cujos contornos não estão nitidamente definidos.

Este artigo busca, portanto, analisar com maior precisão os elementos constituintes do conceito de desenvolvimento, tomando como referência as categorias e terminologias que a biologia explicita em relação aos processos de mudança, como é o caso do conceito em questão. Além do mais, parte do pressuposto que a observação de distinções, relações e mecanismos que ocorrem na dimensão biótica pode contribuir, decisivamente, para uma maior precisão conceitual, bem como influir na dinâmica e nos resultados de processos de mudanças sociais e econômicas.

\section{A trajetória do conceito}

Da Antigüidade até o limiar da Idade Moderna, o conceito de desenvolvimento teve cunho quase estritamente antropológico e teológico. Durante a maior parte desse período, o conceito se referia a um processo de revelação gradual, semelhante ao broto de uma flor que desabrocha aos poucos, o desenrolar de algo envolto, algo presente, mas ainda encoberto (CAIDEN; CARAVANTES, 1985).

A partir de Leibnitz, ${ }^{2}$ em meados do século XVII, os conceitos evolutio e développement passaram a ter um significado de direção e foram associados a espécies de mudanças sequienciais que ocorrem em estágios predefinidos e inevitáveis.

No contexto das filosofias progressistas dos séculos XVIII e XIX, o conceito foi associado a uma concepção otimista segundo a qual os indivíduos e as sociedades seriam capazes de moldar, pelas próprias forças, um novo mundo, cada vez melhor: através da observação meticulosa deveria ser possível identificar e classificar as diversas fases de diferentes processos de desenvolvimento. Além disso, consolidava-se a concepção de que através da especulação, da experimentação e do raciocínio também poderiam ser desvendadas as forças universais atuantes; ou seja, o mundo seria um imenso laboratório! A descoberta de relações de causa e efeito (por acaso ou através de métodos científicos) foi utilizada com vantagens para melhorar a qualidade de vida da humani-

\footnotetext{
${ }^{2}$ Gottfried Wilhelm Leibnitz, nascido em Leipzig em 1-7-1646, trouxe significativas contribuições no campo da filosofia e da matemática na história da humanidade.
} 
dade. Assim, aos poucos, desenvolvimento passou a significar também movimento, processo, mudança e libertação.

Mais recentemente, as doutrinas que embasaram o imperialismo deram ao conceito de desenvolvimento mais um significado, o de transição, durante a qual as chamadas "sociedades tradicionais" foram sendo "ocidentalizadas" pela imposição inescrupulosa de valores e modelos culturais, econômicos e políticos, com o quais se buscava o progresso e a modernização.

Num sentido genérico e sem a pretensão de definir datas e fatos com exatidão, é possível afirmar que a transição das sociedades agrárias e tradicionais para economias urbano-industriais - ou também que o ingresso gradual do mundo na "modernidade" - representou uma ruptura de paradigmas em diversas áreas, como sintetiza o quadro 1 .

Quadro 1 - Ruptura de paradigmas na transição para a 'modernidade'

\begin{tabular}{|c|c|c|}
\hline Características & Era pré-moderna & Era moderna \\
\hline \multirow{9}{*}{ Sociedade } & sociedade agrária & sociedade industrial \\
\hline & Agricultores & operários \\
\hline & proprietários de terras & empresários \\
\hline & trabalho sazonal & ocupação integral \\
\hline & população estagnada & crescimento populacional \\
\hline & Povoamento & urbanização \\
\hline & Analfabetismo & alfabetização \\
\hline & grande família & família \\
\hline & auto-ajuda & Estado social \\
\hline \multirow{5}{*}{ Estado } & reinos feudais & Estados nacionais \\
\hline & Monarquias & democracia das elites \\
\hline & proibição de coalizações & sindicalismo \\
\hline & relações interdinásticas & relações internacionais \\
\hline & tempo e espaço como problema & dominação do espaço/geopolítica \\
\hline \multirow{8}{*}{ Economia } & agricultura/artesanato & Indústria/fábricas \\
\hline & Terra & trabalho \\
\hline & Renda & lucro \\
\hline & trabalho manual & mecanização \\
\hline & economia de subsistência & divisão do trabalho \\
\hline & água/vento & carvão/eletricidade \\
\hline & crescimento nulo & crescimento acelerado \\
\hline & recursos naturais preservados & recursos naturais consumidos \\
\hline \multirow{2}{*}{ Mídia e comunicação } & boca a boca & livro, jornal e revistas \\
\hline & carro de bois, barco a vela & locomotiva, automóvel e avião \\
\hline \multirow{2}{*}{ Idéias } & misticismo, religião & esclarecimento \\
\hline & Mercantilismo & liberalismo \\
\hline
\end{tabular}

Fonte: traduzido e adaptado de Menzel 1998:58-59 
Desse modo, é natural que inúmeras questões relacionadas ao desenvolvimento e ao subdesenvolvimento das nações tenham sido exaustivamente debatidas nos mais diversos contextos. Aliás, por mais que alguns autores considerem os termos "desenvolvimento" e "subdesenvolvimento" ultrapassados, é necessário analisá-los como um par de conceitos complementares, assim como ocorre com ensino/aprendizagem.

Apesar de dispormos de algumas contribuições teóricas importantes sobre diversos aspectos ligados de alguma forma ao desenvolvimento e/ou subdesenvolvimento de países e sociedades, ${ }^{3}$-a exemplo das reflexões de economistas e cientistas sociais clássicos como Adam Smith, David Ricardo e Karl Marx, surgidas antes de 1950 -, é indubitavelmente a partir dessa década que o termo encontra e ocupa lugar de destaque nas ciências sociais aplicadas, contribuindo tanto para a integração de áreas do conhecimento (fomentando a interdisciplinaridade) quanto para a desagregação de posições ideológicas.

Porém, parece imprescindível considerar que:

- os conceitos de desenvolvimento e subdesenvolvimento sempre serão conceitos relativos;

- que jamais haverá uma definição universal para os mesmos;

- que seus valores não são neutros e sim dependentes de variáveis e preconceitos ideológicos;

- que seus conteúdos estão em contínua transformação e que não são as características de um ou outro que são controversas, mas sim a explicação de suas causas.

De modo geral, o "processo de ocidentalização do mundo" (LATOUCHE, 1994), nitidamente perceptível até por volta de 1950, colocou sociedades tradicionais e países menos desenvolvidos que as emergentes economias urbano-industriais diante de um enorme dilema: buscar o ajustamento aos conceitos, parâmetros e modelos ocidentais de desenvolvimento ou manter-se atrelado às tradições, culturas e costumes milenares, ignorando as idéias ocidentais, a tecnologia e o progresso. Nos últimos 50/60 anos, a maior parte dos países acabou se enquadrando com maior ou menor ênfase entre esses dois extremos, representados de um lado por Japão e Turquia, economias que abraçaram a ocidentalização, e de outro, por Albânia, Iêmen e Tibet, países que se fecharam completamente em si mesmos (CAIDEN; CARAVANTES, 1985).

Para além das diferenças de significado e de ênfase do conceito no decorrer da história, o desenvolvimento da humanidade pode ser constatado de forma incontestável nos inúmeros e enormes avanços sociais, econômicos, políticos e técnicos que diferenciam as sociedades primitivas das sociedades pós-modernas, e que continuam ocorrendo com velocidade e abrangência cada vez maiores. Todavia, é necessário reconhecer que o conceito de desenvolvimento - considerado aqui, sobretudo, em sua dimensão socioeconômica ocidental capitalista - tem "data de nascimento": há um certo consenso entre pesquisadores e cientistas sociais de que o discurso de posse de Harry Spencer Truman, ao assumir seu segundo mandato como presidente dos EUA, proferido em 20-11949, instaurou as bases de um novo paradigma mundial. Nesse discurso, Truman configurou, indiretamente, a maior parte do mundo como "subdesenvolvida", ao anunciar um pacote de ajuda técnica, administrativa, econômica e militar dos EUA para os países menos desenvolvidos da África, Ásia e América Latina. Esse programa de governo também ficou conhecido como "Programa Ponto 4", por se tratar do quarto ponto (ou tópico) do referido discurso (DONOVAN 1977, 1982).

Segundo Furtado (1983), o "mito do desenvolvimento" - que levou os países mais pobres a buscar ininterruptamente um nível de vida similar ao dos países mais ricos e ditos "desenvolvidos" - difundiu-se acentuadamente após a II Guerra Mundial. O chamado Plano Marshall, concebido durante a primeira gestão de Truman na presidência dos EUA (1945-48) e que previa diversas formas de auxílio para a reconstrução e o desenvolvimento da Europa Ocidental (KIRKENDALL 1989), foi um precursor e balizador desse paradigma.

3 Do período entre a publicação da obra de Adam Smith, An inquiry into the nature and causes of the wealth of nations, em 1776 - que coincidiu com os primórdios da Primeira Revolução Industrial -, até meados do século XX, quando a ordem econômica mundial havia sido restabelecida após a II Guerra Mundial, as principais questões discutidas no contexto socioeconômico abordavam aspectos específicos daquilo que hoje se entende como desenvolvimento. Exemplos: classes sociais, divisão do trabalho, salário, rendas, meios de produção, riqueza, mais-valia, mercados, preços, capital, lucros, excedentes, acumulação, função do Estado, concorrência, crédito, investimentos, oferta e demanda, entre outros. 
Não há, portanto, como negar que é basicamente a partir desse período que a implementação de políticas e estratégias de desenvolvimento - bem como as discussões teóricas em torno do desenvolvimento socioeconômico de países e regiões - assumiram um lugar de destaque na academia, nos meios políticos e na mídia.

Entretanto, a maior parte das discussões contemporâneas em torno do conceito de desenvolvimento pode ser comparada a um "chover no molhado", tal a profusão de estudos, artigos, publicações, ensaios, teses, teorias, posições, enfoques, enfim, de abordagens já existentes sobre o assunto. No meio acadêmico, os debates abordando esse conceito atingiram proporções que praticamente inviabilizam gerações mais jovens de acompanhar na íntegra as reflexões observadas nas últimas décadas (MENZEL 1995) e entender, na essência, posições arduamente defendidas e mutuamente atacadas pelas diferentes linhas ideológicas (GOUSSAULT; GUICHAUOUA, 1993; NOHLEN; NUSCHELER, 1993).

Do ponto de vista histórico e semântico, o conceito de desenvolvimento já sofreu diversas metamorfoses e tudo indica que essa capacidade de transformação e de adaptação aos diferentes enfoques seja uma de suas principais características, responsável pela sua vitalidade e longevidade como um conceito-chave, ao lado do qual já perfilaram os mais diferentes adjetivos e, agora, também, substantivos.

Todavia, do ponto de vista epistêmico-sistemático, a discussão não avançou na mesma proporção, e a partir de meados da década de 1970, o substantivo "desenvolvimento" começou a ser associado com maior freqüência a adjetivos como "humano", "social", "eco-" e "sustentável" (BRASSEUL, 1989; BRUNDLAND, 1987; COY; KOHLHEPP, 1998; SACHS, 1986). Mais uma vez, o conceito foi reconfigurado, estabelecendo-se relações até então ignoradas, como por exemplo a relação entre desenvolvimento e meio ambiente, entre desenvolvimento e a governança global, ou ainda, entre desenvolvimento e os modelos de médio alcance. Por isso, o termo voltou a ocupar um lugar de destaque nas políticas públicas, na academia, na mídia e em projetos de diferentes grupos e organizações.

No entanto, antes de aprofundar a análise desse conceito-chave numa abordagem epistêmico-sistemática - isto é, antes de buscar esclarecer as reais dimensões do conceito através de um exame baseado na cognição intelectual e na inter-relação de elementos (objetos e processos) - é interessante observar os vários sentidos que lhe foram atribuídos ao longo das últimas cinco décadas, configurando verdadeiros paradigmas do desenvolvimento. Cabe lembrar que durante esse período (últimos 50 anos), o "mundo moderno" ingressou gradativamente na "pós-modernidade", reconfigurando novamente um conjunto de crenças ou paradigmas consolidados em diversas áreas, como sintetiza o quadro 2. 
Quadro 2 - Ruptura de paradigmas na transição para a "pós-modernidade"

\begin{tabular}{|c|c|c|}
\hline Características & Era moderna & Era pós-moderna \\
\hline \multirow{9}{*}{ Sociedade } & sociedade industrial & sociedade terciária \\
\hline & operários & prestadores de serviços \\
\hline & empresários & gestores \\
\hline & ocupação integral & sociedade $2 / 3$ \\
\hline & crescimento populacional & população estagnada \\
\hline & urbanização & comunidades virtuais \\
\hline & alfabetização & analfabetismo tecnológico \\
\hline & família & desagregação familiar \\
\hline & Estado social & desconstrução do Estado social \\
\hline \multirow{5}{*}{ Estado } & Estados nacionais & mundo das sociedades \\
\hline & democracia das elites & oligarquia da mídia \\
\hline & sindicalismo & marginalização sindical \\
\hline & relações internacionais & relações transnacionais \\
\hline & dominação do espaço/geopolítica & dominação do tempo/cronopolítica \\
\hline \multirow{8}{*}{ Economia } & indústria/fábricas & prestação de serviços/finanças \\
\hline & trabalho & tecnologia/conhecimento \\
\hline & lucro & especulação \\
\hline & mecanização & automatização \\
\hline & divisão do trabalho & divisão internacional do trabalho \\
\hline & carvão/eletricidade & atômica/solar \\
\hline & crescimento acelerado & crescimento desacelerado \\
\hline & recursos naturais consumidos & recursos naturais poupados \\
\hline \multirow{2}{*}{ Mídia e comunicação } & livro, jornal e revistas & TV, computador e Internet \\
\hline & locomotiva, automóvel e avião & cabos e satélites \\
\hline \multirow{2}{*}{ Idéias } & esclarecimento & perda da "realidade local" \\
\hline & liberalismo & institucionalismo \\
\hline
\end{tabular}

Fonte: traduzido e adaptado de Menzel 1998:58-59

A ruptura com algumas idéias predominantes em determinadas épocas também parece ser uma característica das estratégias de desenvolvimento experimentadas nos últimos 50 anos em diferentes países e nos mais diferentes contextos. As principais estratégias de desenvolvimento implementadas mundo afora nas últimas cinco décadas são apresentadas de forma bastante concisa através das características sintetizadas no quadro 3. 
Quadro 3 - Principais estratégias de desenvolvimento implementadas após 1950

\begin{tabular}{|c|c|c|c|}
\hline Estratégia básica & Período & Principais elementos & Ênfase \\
\hline Modernização & década de 1950 & $\begin{array}{l}\text { industrialização } \\
\text { (substituição das } \\
\text { importações e fomento às } \\
\text { exportações), revolução, } \\
\text { verde, pólos setoriais e } \\
\text { regionais }\end{array}$ & $\begin{array}{l}\text { setorial, econômica, } \\
\text { orientada para o } \\
\text { crescimento }\end{array}$ \\
\hline Dissociação & década de 1960 & $\begin{array}{l}\text { Desenvolvimento do } \\
\text { mercado interno, self } \\
\text { reliance }\end{array}$ & política \\
\hline $\begin{array}{l}\text { Equacionamento } \\
\text { das necessidades } \\
\text { básicas }\end{array}$ & década de 1970 & $\begin{array}{l}\text { Orientação para a miséria } \\
\text { e grupos marginalizados } \\
\text { específicos, inclusão e } \\
\text { participação }\end{array}$ & regional e social \\
\hline Ajuste estrutural & década de 1980 & $\begin{array}{l}\text { Desregulamentação, } \\
\text { flexibilização, } \\
\text { desestatização, } \\
\text { equacionamento da dívida, } \\
\text { balanço de pagamentos e } \\
\text { controle da inflação } \\
\text { interna }\end{array}$ & econômica \\
\hline $\begin{array}{l}\text { Desenvolvimento } \\
\text { sustentável }\end{array}$ & década de 1990 & $\begin{array}{l}\text { Desenvolvimento } \\
\text { socioeconômico } \\
\text { participativo e preservação } \\
\text { do meio ambiente e } \\
\text { recursos naturais }\end{array}$ & $\begin{array}{l}\text { regional, ambiental e } \\
\text { socioeconômica }\end{array}$ \\
\hline Governança global & fim dos anos 1990 & $\begin{array}{l}\text { novas formas da regulação } \\
\text { global, conferências } \\
\text { mundiais, Agenda } 21\end{array}$ & $\begin{array}{l}\text { global, política e } \\
\text { ambiental }\end{array}$ \\
\hline $\begin{array}{l}\text { Modelos de médio } \\
\text { alcance }\end{array}$ & primórdios do século XXI & $\begin{array}{l}\text { regiões emergentes, } \\
\text { clusters, arranjos } \\
\text { produtivos, pacto } \\
\text { socioterritorial, } \\
\text { aprendizagem }\end{array}$ & setorial, socioterritorial \\
\hline
\end{tabular}

Fonte: elaborado pelo autor

É evidente que esse quadro-síntese omite uma infinidade de especificidades, mas nele estão evidenciadas as principais características e ênfases de cada estratégia em diferentes períodos. Apesar do quadro apresentar os principais paradigmas do desenvolvimento em ordem cronológica, isso não significa que os chamados "países 
em desenvolvimento" seguiram necessariamente essa ordem ou que adotaram todas as estratégias na implementação de seus processos de desenvolvimento. Além disso, é necessário levar em conta que nesse diagrama são apresentados modelos que seguem orientações ideológicas e políticas antagônicas.

Outro fato que ainda precisa ser destacado é que essa transição (ou mutação constante de um paradigma a outro) evidencia as enormes dificuldades dos países de efetivamente viabilizarem ou concretizarem o almejado desenvolvimento.

Nesse sentido, cabe perguntar: será a agenda do desenvolvimento incompatível com os planos e estratégias de países e regiões? Tomando o Brasil como exemplo, os questionamentos sobre as estratégias de desenvolvimento se cristalizam: como é possível que o país, com todos os seus recursos disponíveis, apresentando seguidos recordes de produção e produtividade nos setores agrícola e industrial, seja a sociedade mais desigual do planeta? A superação do apartheid social parece ser o grande desafio do país nesse novo século, pois o que se verifica é que enquanto uma parte dos brasileiros dorme com fome, a outra dorme com medo.

Em estudo recentemente divulgado, ${ }^{4}$ são apresentados dados assustadores sobre a iniqüidade social brasileira. Pesquisadores do Instituto de Pesquisa Econômica Aplicada (Ipea) criaram um indicador chamado Patamar Mínimo de Existência Digna (Pmed) para avaliar o processo recente de desenvolvimento do país, que pressupõe: domicílio próprio adequado (construído com material permanente, com água encanada, banheiro, esgoto, energia elétrica, telefone, fogão, geladeira, filtro de água, rádio e televisão), renda familiar per capita de (no mínimo) 1,5 salário mínimo, escolaridade adequada e cobertura previdenciária.

Tomando por base os dados da Pesquisa Nacional por Amostragem de Domicílios (Pnad), a pesquisa evidenciou que, mantido o ritmo de desenvolvimento registrado nos últimos anos, a população das áreas urbanas brasileiras necessitaria, nada mais, nada menos do que 290 anos para atingir o referido patamar. Tomando como referência exclusivamente a população rural brasileira, a situação é estarrecedora: seriam necessários quase quatro milênios (3.899 anos) para que essa população rural conseguisse ser classificada como minimamente digna, ainda de acordo com o Pmed.

Esses dados evidenciam que a temática do desenvolvimento, além de atual e duradoura, é uma questão crucial no Brasil. Desenvolvimento parece ser um must. Dificilmente um candidato a qualquer cargo político pode se dar ao luxo de omitir esse termo em seus discursos, planos e intenções. Da mesma forma, acontece com os representantes que já estão no poder, enquanto a academia e a sociedade aparentemente seguem "à reboque" nas discussões.

Apesar de todo esse destaque, a ubiqüidade e a ambigüidade das discussões parecem, muitas vezes, estar em correlação direta: desenvolvimento é um conceito utilizado nos mais diferentes contextos, aparentemente sem maiores preocupações quanto à exatidão de sua concepção. $\mathrm{O}$ uso abusivo e indiscriminado desse conceito tão relevante é, à primeira vista, um fenômeno universal. Não há como negar que desenvolvimento seja um termo com muito apelo, mas o curioso é que o termo seja usado com maior intensidade exatamente ali onde ele propicia maior confusão: muitas vezes é empregado explicitamente como uma palavra-chave, para dar uma certa consistência e peso a comunicados oficiais, notícias ou trabalhos acadêmicos, sem que lhe seja atribuída uma relação indiscutível. Nesse sentido, "desenvolvimento" parece ser um termo genérico que todos subentendem automaticamente, sem que lhe sejam atribuídas dimensões conceituais básicas!

Evidentemente, essa imprecisão conceitual é, sob alguns aspectos, vantajosa, sobretudo nos meios políticos, pois não se definem relações concretas, o espaço para as mais diferentes interpretações fica garantido e as justificativas para qualquer resultado não podem ser refutadas. Aparentemente, quando se fala em desenvolvimento, viceja, vigoroso, um duplo faz-de-conta: enquanto alguns agem em prol do mesmo, outros crêem que algo está sendo feito, sem que as dimensões essenciais do conceito tenham sido indubitavelmente explicitadas. No entanto, uma condição essencial para um relacionamento não litigioso entre integrantes de uma sociedade é a utiliza${ }^{4}$ Iniqüidade social no Brasil: uma aproximação e uma tentativa de dimensionamento, de Ronaldo Coutinho Garcia, do Ipea, (PRADO,
2002). 
ção de conceitos que diferenciam claramente as dimensões e intenções abrangidas das dimensões e intenções não abrangidas pelos conceitos, políticas e estratégias em questão.

Em suma, quando se trata do termo "desenvolvimento", duas características básicas de qualquer conceito, clareza e precisão, parecem estar em contradição direta com a intensidade e a freqüência de seu uso. Em outras palavras, a intensidade e a frequiência do uso desse conceito não devem nem podem ser consideradas como uma prova irrefutável de sua utilidade. O desgaste desse conceito-chave é tal, que alguns crêem que é chegada a hora de "escrever seu obituário" (SACHS, 2000, p.11).

Enfim, devemos considerar que em torno do conceito de desenvolvimento socioeconômico estabeleceu-se, tanto na retórica política quanto na idiomática jurídica, bem como em muitos discursos acadêmicos e na terminologia oficial, uma forte tendência natural para indicar um contexto relativamente impreciso, aproximado, indefinido, ambíguo, que permite as mais diversas interpretações.

Apesar de todo esse desgaste conceitual, este artigo se propõe a apresentar de uma forma diferenciada o entendimento do que vem a ser desenvolvimento, enfatizando não a simples apresentação de conceitos e definições difusas, carregadas de preconceitos ideológicos e de sentido restrito e mutante, como foi feito até aqui, mas procurando apresentar o conceito numa abordagem epistêmico-sistemática que parece lhe dar um sentido mais claro.

\section{Processos de mudança: uma abordagem epistêmico-sistemática ${ }^{5}$}

Inicialmente, cabe lembrar que o termo "desenvolvimento" é originário de um conjunto de conceitos largamente utilizados na biologia. Ali os termos "desenvolvimento", "crescimento" e "evolução" são integrantes de uma família de conceitos onde cada um deles explicita processos de mudança perfeitamente distintos entre si. Essas diferenciações dizem respeito:

- às características da mudança, que pode ser de ordem quantitativa (número, tamanho e abrangência) ou de ordem qualitativa (tipo, composição e estado);

- aos seres ou objetos submetidos a essas mudanças, que dizem respeito tanto a indivíduos quanto a populações ou coletividades;

- às formas de como essas mudanças se processam, que ocorrem exclusivamente mediante determinadas combinações objetos/aspectos.

A observação das diferenças, das variações e dos mecanismos existentes entre os processos de mudança mencionados (crescimento, desenvolvimento e evolução), comumente observáveis no âmbito do mundo biótico, propicia uma maior clareza conceitual; ou seja, ali, as diversas fases e as características da mudança estão catalogadas em níveis e ramificações específicas, de tal forma que todas as fases e todos os processos podem ser sistemática e conceitualmente explicitados (ver figura 1).

Tomando por base a direção geral de processos de mudança que se enquadram na acepção mais genérica daquilo que se entende por desenvolvimento, podemos excluir de antemão os processos de deterioração, diminuição, redução, decadência ou regressão; isto é, processos de mudança com conotação negativa, de involução, retrocesso ou regressão.

Assim, num primeiro nível da classificação conceitual podemos distinguir de forma inequívoca entre processos de mudança que dizem respeito ao "tamanho" da mudança (significando uma variação quantitativa) e processos de mudança que dizem respeito às "características" da mudança (significando uma alteração qualitativa). Se considerarmos que tanto indivíduos quanto populações ou coletividades estão sujeitos tanto a variações quantitativas quanto a alterações qualitativas, teremos, num segundo nível da classificação, uma subdivisão conceitual nitidamente distinguível entre "crescimento", "desenvolvimento" e "evolução".

\footnotetext{
${ }^{5}$ Como o próprio subtítulo indica, não se pretende apresentar aqui simplesmente (mais) um conceito para o termo desenvolvimento; o objetivo é fazer uma abordagem integrada, analisando de forma subjetiva e cognitiva a natureza, as etapas e os limites do conceito num contexto sistêmico.
} 
Ao analisarmos a ramificação quantitativa dos processos de mudança, vamos constatar que tanto indivíduos quanto populações estão sujeitos ao "crescimento", embora os mecanismos pelos quais esse processo se dá sejam de natureza diferenciada. Indivíduos crescem pela apropriação de matéria de seu meio, formando células, tecidos e órgãos, enquanto populações crescem pela incorporação de indivíduos, compondo grupos ou coletividades maiores. Portanto, para que haja crescimento (dimensão quantitativa), é absolutamente necessário que os mecanismos individuais de apropriação e coletivos de incorporação sejam acionados.

Nos dois casos de crescimento (de indivíduos e de populações) prevalece o princípio de que a reprodução dos mecanismos de apropriação e incorporação gera, respectivamente, a acumulação ou a expansão de elementos preexistentes. Através da repetição contínua desses mecanismos surge a ampliação (quantitativa, física) daquilo que já existe, ou seja, "mais do mesmo", no contexto de uma equação ou jogo de resultado zero com o meio.

Diferentemente do que ocorre com processos de mudança que se enquadram nos moldes da variação quantitativa, nos processos de mudança qualitativos a diferenciação entre indivíduos e populações é de fundamental importância.

Para os indivíduos de uma mesma espécie valem, sob condições normais, limites relativamente uniformes quanto ao intervalo de tempo entre o seu nascimento e a sua morte, uma vez que o ciclo de vida dos mesmos segue uma trajetória típica para a espécie. Em contrapartida, populações não estão necessariamente sujeitas a esse determinante natural, haja vista que seu surgimento e seu desaparecimento decorrem de diferentes interrelações. O surgimento e o desaparecimento de populações não resulta nem se explica pela leitura de um aspecto específico (como por exemplo o nascimento, a evolução ou a morte) de um único componente; por isso, também não há um limite relativamente uniforme para o intervalo de tempo relativo à existência de populações. Enquanto novos componentes substituírem aqueles que vão sendo descartados, está garantida a existência de populações, mesmo que a dimensão e a estrutura de cada faixa etária varie no decorrer do tempo. Portanto, diante do exposto, podemos afirmar que as alterações qualitativas são de natureza diferenciada em indivíduos e populações. 


\section{Figura 1 - O conceito de desenvolvimento num contexto epistêmico-sistemático}

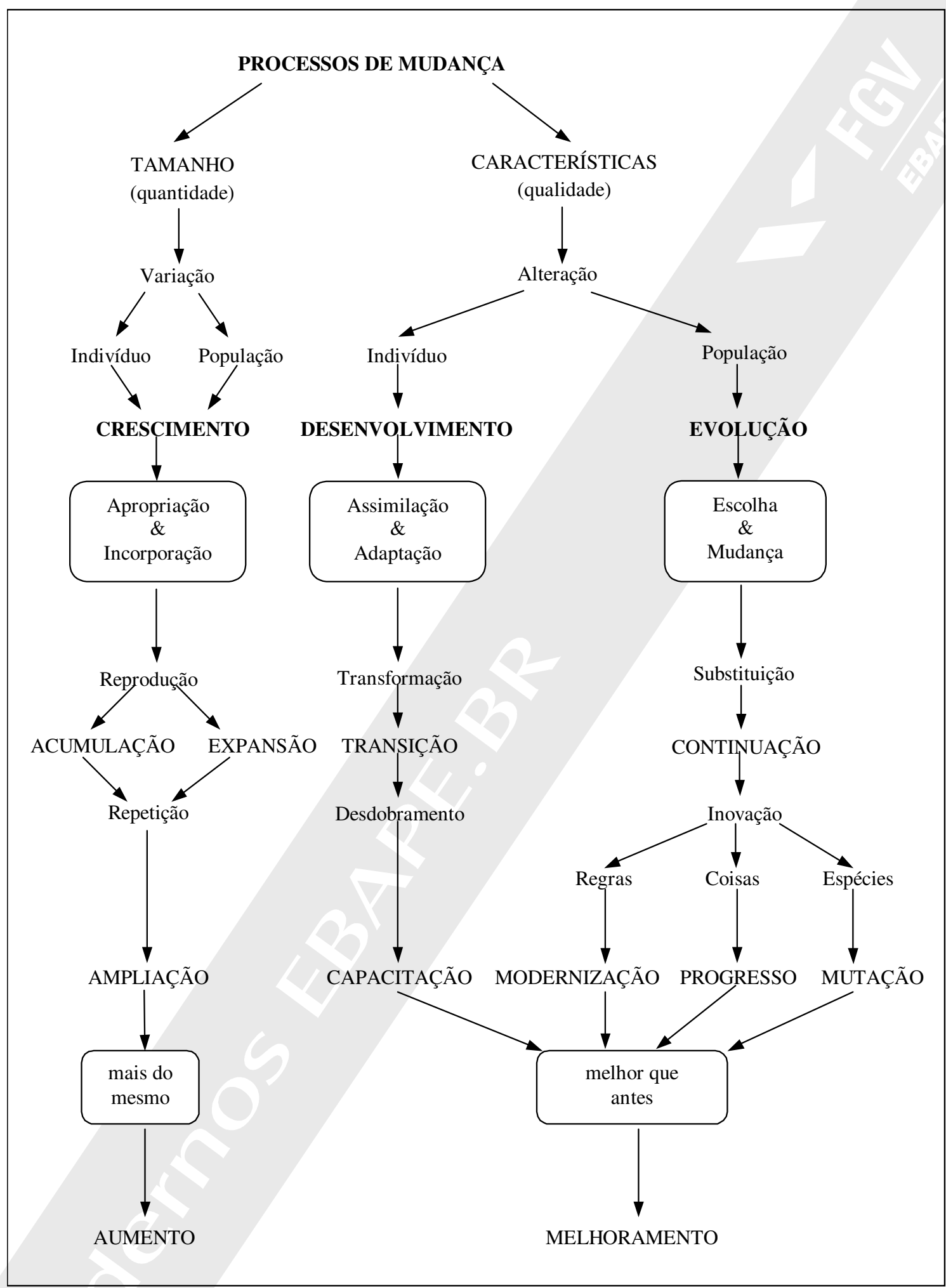

Fonte: Heidemann (1993, p.6).

A partir dessa constatação convencionou-se denominar como desenvolvimento a mudança da capacidade individual no decorrer de sua própria biografia; ou seja, o desenvolvimento é consequiência natural da aplicação de um mecanismo de assimilação e adaptação de habilidades individuais preexistentes às necessidades postas, uma espécie de upgrade de habilidades. 
Normalmente, essas mudanças individuais ocorrem em etapas denominadas de transições, de acordo com fases típicas de cada espécie (por exemplo: ovo > larva > pupa > imago; ou também: infância > puberdade > adolescência $>$ fase adulta $>$ velhice) e correspondem a um desdobramento de habilidades, no sentido do indivíduo conseguir enfrentar as situações adversas de cada fase.

Cabe ressaltar que o mecanismo da assimilação e adaptação não se restringe a processos da esfera somática (relativos ao organismo); ele também se aplica às experiências abstratas vividas pelo indivíduo. É necessário considerar que além desses aspectos, este mecanismo também propicia ao indivíduo posicionar-se perante situações que não foram vivenciadas em sua própria biografia, bem como tomar decisões baseadas em suposições que não são fruto de suas próprias experiências. Nesse sentido, o desenvolvimento significa o desdobramento de habilidades já existentes, que capacitam o indivíduo a atuar com uma variedade de requisitos de forma sustentável num contexto que para ele é obscuro, difuso, inconstante ou adverso.

Cabe destacar também uma diferença entre o desenvolvimento somático (relativo ao corpo) e o desenvolvimento cognitivo (relativo ao conhecimento). Enquanto o ramo somático do desenvolvimento individual conduz a um conjunto normativo típico da espécie em relação à estrutura corporal - antes que se instale um processo de envelhecimento -, o ramo cognitivo do desenvolvimento individual é muito mais influenciável por demandas e ingerências contextuais, não envelhecendo, mas podendo tornar-se obsoleto.

Já a "evolução", entendida no contexto de mudanças qualitativas que envolvem populações ou coletividades, está baseada fundamentalmente em mecanismos de escolha e mudança, ou seja, na substituição de elementos precursores por elementos sucessores no decorrer de gerações. Trata-se de um processo contínuo, onde inovações não ocorrem exclusivamente no decorrer de biografias individuais, mas marcam as mudanças nas características próprias de populações, onde a faculdade ou capacidade de uma nova geração diverge das faculdades e capacidades observadas em gerações anteriores. Nas populações bióticas esse processo leva, ao longo do tempo, à mutação das espécies, sobretudo, quando tais mudanças, melhorias ou qualificações são incorporadas pelas novas gerações.

Ao considerar as inovações ou mudanças qualitativas de coletividades que ocorrem nas dimensões extrasomáticas, observa-se o surgimento de novas regras (processos, instâncias) ou de novas coisas (ferramentas, equipamentos). Assim, no surgimento de novas regras e coisas transparece o princípio de que inovações são adotadas como decorrência do envelhecimento e desgaste de modelos existentes, em cujos substitutos se manifestam as mudanças na forma de modernização organizacional ou de progresso técnico, respectivamente.

Além disso, devemos considerar que o "desenvolvimento" e a "evolução" se diferenciam também nos seguintes aspectos:

- enquanto a mutação das espécies, o progresso técnico e a modernização organizacional podem ser considerados "respostas" do meio às "perguntas" (ou demandas) de uma população, a capacitação individual deve ser entendida como uma "resposta" do indivíduo às "perguntas" (ou desafios) do meio;

- enquanto a mutação, o progresso e a modernização (como processos coletivos), muitas vezes, sacrificam temporariamente sua própria consistência diante de um amplo espectro de adversidades, a capacitação (como processo individual), normalmente, torna o indivíduo mais forte quando tem sucesso na adversidade; e

- enquanto o desenvolvimento individual segue um esquema típico da espécie e tem resultados perfeitamente previsíveis, na maior parte dos processos evolutivos não é possível identificar com maior exatidão esquemas e processos de mudança preconcebidos.

\section{Considerações finais}

$\mathrm{Na}$ biologia, o objetivo da diferenciação entre crescimento, desenvolvimento e evolução refere-se, em boa parte, à explicitação de diferentes mecanismos de apropriação e incorporação, de assimilação e adaptação, e de escolha e mudança, respectivamente. Isso significa também que a ocorrência de um processo de mudança espe- 
cífico (crescimento, desenvolvimento ou evolução) nada mais é do que o efeito, o resultado, o entrar em ação do respectivo mecanismo. Logo, a condição essencial e básica para a ocorrência ou para o fomento de um determinado processo de mudança pressupõe o acionamento do mecanismo correspondente.

Considerando a possibilidade de se fazer alguns paralelos entre a dimensão biótica e a dimensão social, podemos comparar, por exemplo, aquilo que o modelo de Heidemann (1993) configura como indivíduo com uma organização isolada, e população com um conjunto de organizações sociais. Segundo esse modelo, todo processo de mudanças que se resume num aumento quantitativo daquilo que já existe (seja uma máquina do mesmo tipo numa empresa, seja uma empresa do mesmo tipo numa cidade) configura um processo de crescimento. Já o conceito de desenvolvimento é reservado exclusivamente para identificar os processos de mudança qualitativa no âmbito individual da organização; ou seja, desenvolvimento ocorre quando essa entidade passa a ter uma capacidade qualitativamente diferenciada em relação à sua condição anterior. Finalmente, o conceito de evolução identifica processos qualitativos de mudança (melhorias) no contexto de coletividades.

Por analogia, poderíamos pressupor que tanto o crescimento de uns quanto o de outros (isto é, indivíduos e coletividades) só é concebível quando os respectivos mecanismos são acionados; isto é, não há crescimento sem que estejam presentes e atuantes as condições de apropriação ou incorporação. Da mesma forma, a assimilação e a adaptação são fatores essenciais ao desenvolvimento de indivíduos ou organizações, assim como a escolha e a mudança são de importância capital para que haja evolução de populações ou coletividades.

Em diversos sentidos se observa uma correlação entre os processos de crescimento, desenvolvimento e evolução, mas a diferenciação estabelecida no mundo biótico comprova que atribuir a ocorrência dessas mudanças a um mecanismo único e simplificado é uma conclusão precipitada. A observação dessas diferenciações é de crucial importância, não apenas quando se visa descrever processos de mudança, mas, sobretudo, quando se pretende influenciar processos de mudança, tanto no mundo biótico quanto no contexto social.

Com base no exposto anteriormente, podemos concluir que no contexto social a discussão e a formulação de estratégias ou políticas de crescimento, desenvolvimento ou evolução têm como pressuposto básico a definição precisa daquilo que se entende em cada caso. Enquanto não ocorrer essa explicitação conceitual, toda e qualquer ação pode ser apresentada como uma contribuição ao desenvolvimento socioeconômico, sem correr o risco de ser refutada, independentemente de sua real contribuição para a melhoria das condições de vida de indivíduos ou populações. Não é difícil imaginar que nesse cenário de indefinições e imprecisões ocorram absurdos, utopias e ações totalmente inócuas, ainda que muitas vezes se pareçam com processos de desenvolvimento, crescimento ou evolução.

Assim, conclui-se que o desenvolvimento socioeconômico, um termo que muitas vezes também é utilizado como sinônimo de crescimento e de evolução - ou também como um processo de mudanças subentendido automaticamente em suas mais diversas concepções e conotações - só ocorre quando os mecanismos de apropriação e incorporação, de assimilação e adaptação e de escolha e mudança estão presentes e são acionados.

Entretanto, como é possível constatar se realmente ocorreu um processo de desenvolvimento socioeconômico, entendido aqui como melhoria quantitativa e qualitativa das condições de vida de indivíduos e sociedades? Ora, é evidente que qualquer política ou estratégia de desenvolvimento social e econômica precisa definir de antemão três aspectos fundamentais: as características, a dimensão e o prazo em que essas mudanças pretendidas deverão se concretizar. A avaliação de políticas de desenvolvimento e a avaliação do desempenho dos responsáveis por sua implementação passa, indubitavelmente, pela observação desses parâmetros.

Além do mais, podemos extrair do exposto até aqui que os processos de desenvolvimento social e econômico que se referem exclusivamente às mudanças quantitativas estão fadados ao esgotamento, por causa da dimensão finita de recursos naturais existentes em nosso planeta. Apesar de todos os avanços genéticos e técnicos que a humanidade tem experimentado, a característica desse ramo do processo de mudanças é a insustentabilidade. Aqui, faz sentido lembrar das palavras do célebre líder indiano, Gandhi (apud LISBOA, 1995, p.8): "o que existe no mundo é suficiente para satisfazer às necessidades de todos, porém não à cobiça de alguns". Já quanto aos processos de mudança social e econômica que preconizam aspectos qualitativos, estão garantidos enormes campos de ação; é absolutamente necessário buscar avanços nesse sentido. 
Por último, é necessário levar em conta que, se por um lado o desenvolvimento social e econômico de determinadas sociedades ou regiões pode ser creditado a uma série de estratégias, políticas e mecanismos implementados com sucesso, por outro lado, o desenvolvimento socioeconômico também é, em boa parte, decorrência de uma série de coincidências favoráveis que ocorrem de forma aleatória, desordenada e abundante num determinado espaço físico e intervalo temporal, como comprovam inúmeros exemplos da dimensão biótica e abiótica. 


\section{Referências}

BOISIER, S. Desarrollo (local): de qué estamos hablando? In: BECKER, D. F.; BANDEIRA, P. S. Desenvolvimento local/regional - determinantes e desafios contemporâneos. Santa Cruz do Sul: Edunisc, v.1, p.151-185, 2000.

BRASSEUL, J. Introduction à l'économie du development. Paris: [s.n.], 1989.

BRUNDLAND, G. H. Nosso futuro comum. Nova York: ONU - Comissão Mundial sobre Meio ambiente e Desenvolvimento, 1987.

CAIDEN, G. E.; CARAVANTES, G. R. Reconsideração do conceito de desenvolvimento. Caxias do Sul: [s.n.], 1985.

COY, M.; KOHLHEPP, G. Nachhaltige Entwicklung. In: SCHOLZ, F.; KOOP, K. (Ed.). Rundbrief Geographie, n.149, p.29-30, 1998.

DONOVAN, R. J. Conflict and crisis. The presidency of Harry S. Truman (1945-48). New York: [s.n.], 1977.

Tumultuous years. The presidency of Harry S. Truman (1949-53). New York: [s.n.], 1982.

FURTADO, C. 0 mito do desenvolvimento econômico. 2 ed. Rio de Janeiro: Paz e Terra, 1974.

GOUSSAULT, Y.; GUICHAOUA, A. Sciences sociales et development. Paris: [s.n.], 1993.

HEIDEMANN, C. Die Entwicklungsvokabel - Redenschmuck oder Gedankenstütze? Diskussionspapier, Institut für Regionalwissenschaft der Universität Karlsruhe, Karlsruhe, n.23, 1993.

KIRKENDALL, R. S. The Harry Spencer Truman Encyclopedia. Boston: [s.n.], 1989.

LATOUCHE, S. A ocidentalização do mundo. Petrópolis:[s.n.], 1994.

LISBOA, A. M. Desenvolvimento. Uma idéia subdesenvolvida. Florianópolis: CNM/UFSC, 1995. Manuscrito.

MENZEL, U. Geschichte der Entwicklungstheorie. Einführung und systematische bibliographie. 3. nochmals überarbeitete, erweiterte und aktualisierte Auflage. Hamburg, 1995.

MENZEL, U. Globalisierung versus Fragmentierung. Frankfurt am Main: Suhkamp, 1998.

NOHLEN, D., NUSCHELER, F. Handbuch der dritten welt. Band 1: grundprobleme, theorien, strategien. 1., durchgesehener Nachdruck der 3. Auflage. Bonn, 1993.

NUSCHELER, F. Lern und arbeitsbuch entwicklugspolitik. Bonn: Bundeszentrale für politische Bildung, 1995.

PRADO, M. C. R. M. Iniqüidade social: dados dantescos. Gazeta Mercantil, p.A-3, 7 nov. 2002.

SACHS, I. Ecodesenvolvimento: crescer sem destruir. São Paulo: [s.n.], 1986.

SACHS, W. Dicionário do desenvolvimento. Guia para o conhecimento como poder. Petrópolis: [s.n.], 2000. 